\title{
İşletmelerde İnovasyon Faaliyetlerini Etkileyen Parametrelerin Belirlenmesi ve Önceliklendirilmesi
}

\author{
Murat OTURAKÇI*1 \\ ${ }^{1}$ Adana Bilim ve Teknoloji Üniversitesi, Mühendislik Fakültesi, Endüstri Mühendisliği Bölümü, \\ Adana
}

$\ddot{\mathbf{O} z}$

Geliş tarihi: $12.02 .2018 \quad$ Kabul tarihi: 29.06 .2018

Bu çalışmada, işletmelerin inovasyon faaliyetlerine etki eden parametreler belirlenip önceliklendirilmiştir. Yapılan literatür araştırması sonucunda çalışan özellikleri, işletme özellikleri ve işletme dışı özellikleri olarak üç ana grup olarak ele alınan parametreler ve bu parametrelere bağlı olan alt parametreler belirlenmiştir. Beş farklı sektörden uzmanlar ile görüşülerek ilgili parametreler Analitik Hiyerarşi Prosesi (AHP) yöntemi kullanılarak puanlanmış ve sonuçlar sektör ortalama ağırlıkları alınarak yorumlanmıştır. Çalışmanın sonuçlarına göre çalışan özellikleri işletmelerin inovasyon faaliyetlerine etki eden en önemli ana parametre olarak belirlenmiş ve bütün alt parametreler arasında çalışan özelliklerine ait olan deneyim, eğitim düzeyi ve sayısı en öncelikli parametreler olarak ağırlıklanmıştır. Çalışma işletmelerin inovasyon faaliyetlerini yürütürken etkilendikleri parametrelere önem vermeleri açısından karar vericilere 1 şı tutması yönünden önem taşımaktadır.

Anahtar Kelimeler: İnovasyon, Analitik hiyerarşi prosesi, İnovasyon parametreleri

\section{Determination and Prioritization of Parameters that Affect Innovation Activities in Companies}

\begin{abstract}
In this study, parameters that affect innovation activities in companies are determined and prioritized. According to literature search, main parameters are detected such as employee characteristics, company characteristics and environmental characteristics and their sub characteristics. Parameters are scored by specialist from five different sectors with Analytical Hierarchy Process (AHP) and results are interpreted according to sector averages. Ultimately, employee characteristics are calculated as the most imporant main parameter and among all sub parameters experience, level of education and number of employees which are the sub parameters of employee characteristics are calculated as the most important parameters. This study carries a genuine value for decision makers while they are conducting their innovation studies.
\end{abstract}

Keywords: Innovation, Analytical hierarchy process, Innovation parameters

\footnotetext{
*Sorumlu yazar (Corresponding author): Murat OTURAKÇI, moturakci@adanabtu.edu.tr
} 


\section{GíRiş}

Teknolojik gereksinimlerin engellenemeyen hızı, işletmelerin son teknolojiyi yakalamaları için rekabet unsurunu çok önemli bir faktör haline getirmiştir. Günümüzde işletmeler, teknolojinin nimetlerinden faydalanmak ve yoğun rekabet içerisinde sindirilmemek için her alanda farklı strateji uygulamaktadırlar. Yönetimsel, organizasyonel ve iş süreçleri içerisindeki verimlilik artırıcı çalışmaların yanı sıra, inovasyon kavramının işletme kültürü içerisine yerleşmiştir. İşletmelerin inovasyon yönetimi çerçevesinde gerçekleştirdikleri çalışmalar sürekli geliştirme ve iyileştirme kapsamında hız kazandığından, gerek akademik gerekse sektörel çalışmalarda inovasyon kavramı ilginin odağı haline gelmiştir. İnovasyon kavramı için birçok temel tanımlama mevcut olsa da, Rogers [1] inovasyonu; bir fikir, uygulama veya bir nesnenin yeni olarak, bireysel ya da toplumsal biçimde benimsenerek algılanması olarak tanımlamıştır. Algılanan inovasyonun yayılması ise toplum, işletmeler, pazarlar ve ülkeler tarafindan yaygın bir şekilde kullanımı sonucuyla ortaya çıkmaktadır.

İşletmelerin temel olarak sürdürülebilir büyüme temel hedefiyle inovasyon çalışmalarına yön vermelerinin ülke ekonomisi ve kalkınmasında rolü çok büyüktür. Türkiye'de inovasyon kavramının önemini ve etkisini vurgulamak üzere, iki yılda bir üç dönemlik periyotlarla derlenen yenilik araştırmasının son raporuna göre yenilikçi girişimlerin oranı \%61,5; girişimlerin \%47,3'ü ürün ve/veya süreç yeniliği faaliyetinde bulunduğu; girişimlerin \%50,8'i organizasyon ve/veya pazarlama yeniliği faaliyetinde bulunduğu; girişimlerin \%27,6'sı finansal destek aldığı; ürün ve/veya süreç yeniliği faaliyetinde işbirliği oranı $\% 23$ şeklinde gerçekleştiği belirtilmiştir [2].

Rekabet unsurunun yüksek olduğu teknolojik çağda işletmeler ürünlerini, hizmetlerini, süreçlerini, pazarlama stratejilerini ve organizasyonlarını güncel ve rekabet edebilir tutmak durumundadırlar. İşletmeler, inovasyon yapma kararları neticesinde birçok faktör ile karşılaşırlar. Bazı işletmeler gerçekleştirdikleri inovasyon sonucunda verimli sonuçlar elde edebilirken, bazıları ise tam tersi sonuçlarla karşılaşabilirler. İşletmelerin karar verme mekanizmalarına ve inovasyon süreçlerine etki eden bir takım faktörlerin olduğu bu noktada ortaya çıkmaktadır.

İşletmelerin inovasyon yapma eğilimlerini ölçen, bu eğilimlere etki eden faktörlerin araştırıldığ birçok çalışma bulunmaktadır. Çetin ve Gedik [3], inovasyon yapmada işletme yaşı ve işletmede çalışan sayısının etkisini araştırmışlardır. Şendoğdu ve Öztürk [4], Konya İli'nde faaliyet gösteren KOBİ'lerin inovasyon yapma eğilimi ile inovasyon performans başarı derecesi arasında ilişki olup olmadığını çalışan sayısı, işletmenin yaşı, yöneticilerin eğitim düzeyi, banka destekleri parametreleri üzerinden değerlendirmişlerdir. Kılıç ve Keklik [5], firma büyüklüğü, firma yaşı, hukuki statüsü, faaliyet alanı, Ar-Ge'ye ayrılan pay faktörlerini inovasyon uygulamalarına etkisini belirli bir örneklem üzerinde ölçerek değerlendirmişlerdir. Örücü ve arkadaşları [6], KOBI'lerin çalışan sayıları ve yasal yapılarındaki farklılıkların inovasyon yapmayı ne derecede etkilediğini ve Ar-Ge'ye ayırdıkları pay ile inovasyon stratejileri arasındaki ilişkiyi incelemiştir. Çalıpınar ve Baç [7], çalışan sayısı, ihracat gelirleri, reklam harcamaları, Ar-Ge harcamaları, patent harcamaları, işletme yaşı ve toplam kurulan dış ortaklık sayısı faktörlerin, işletmelerin inovasyon yapma sayılarına etkileri incelenmiştir. Romero ve Martinez-Roman [8], KOBI'lerde inovasyona etki eden faktörleri çalışanların temel özellikleri, şirketlerin özellikleri ve dış çevre özellikleri temel gruplarına ayırarak değerlendirmiştir. Shefer ve Frenkel [9]; Ar-Ge yatırımları, işletmenin büyüklüğü, yaşı ve bulunduğu sektörün inovasyon faaliyetlerini etkilediğini savunmuştur. Hameed ve Counsell [10], inovasyonun aşamaları, tipleri, organizasyon tipleri ve büyüklüklerinin ve bu tip koşullardaki değişikliklerin işletme faaliyetlerini etkilediğini vurgulamışlardır. Garcia ve arkadaşları [11], cinsiyet farklılığının araştırma ve geliştirme takımları içerisindeki inovasyona etkisini 
araştırmışlardır. Marvel ve arkadaşları [12], çalışmalarında, girişimcilerin cinsiyeti ve eğitim tiplerinin yeni işletmelerdeki inovasyon faaliyetlerine olan etkilerini gözlemlemişlerdir. Subramanian ve arkadaşları [13], eğitim seviyesi, cinsiyet, teknolojik çeşitlilik parametrelerinin inovasyon performansina olan etkisini araştırmışlardır.

Literatür çalışmaları incelendiğinde, ilgili çalışmaların işletmelerde inovasyon faaliyetlerini etkileyen parametrelerin istatistiksel olarak analiz edilmesine yoğunlaştığı görülmüştür. $\mathrm{Bu}$ çalışmada, literatürden derlenen parametreler arasında çok kriterli karar verme yöntemi ile önceliklendirilmesi amaçlanmıştır. Böylelikle bu çalışma, işletmelerin inovasyon faaliyetlerine etki eden ilgili parametrelerin önem siralarının belirlenmesi ile inovasyon yönetimi kapsamında karar vericilere $1 s ̧ \mathrm{k}$ tutması yönünden önem taşımaktadır.

\section{MATERYAL VE METOT}

\subsection{Materyal}

İşletmelerin inovasyon faaliyetlerine etki eden parametrelerin belirlenip önceliklendirildiği bu çalışmada farklı sektörlerde faaliyet gösteren beş ayrı işletmenin uzman görüşlerine yer vererek veriler sağlanmıştır. Uzmanlar ilgili işletmelerde müdür, yönetici, direktör gibi karar verici konumundadırlar. Uzman olarak adlandırılan karar vericilere, derlenen parametreler üzerinden ikili kıyaslamalar yaptırılarak puanlandırma ve önceliklendirme yaptırılmıştır.

İşletmelere etki eden parametreler çalışan özellikleri, işletme özellikleri ve işletme dışı özellikleri şeklinde üç ana gruba ayrılmıştır. Çalışan özellikleri; çalışan sayısı, deneyimi, yaşı, cinsiyeti ve eğitim düzeyi olarak; işletme özellikleri; işletmenin büyüklüğü, sektörü, Ar-Ge bütçesi, yaşı ve teknolojik altyapısı olarak; İşletme dışı özellikler ise banka desteği, kanun/devlet desteği, rekabet ve müşteri olarak alt parametreleri belirlenmiştir. İşletmelerin inovasyon faaliyetlerine etki eden parametreler Çizelge 1' de gösterilmiştir.

Çizelge 1. İnovasyon faaliyetlerine etki eden parametreler

\begin{tabular}{|c|c|}
\hline Grup Ad1 & Parametre \\
\hline \multirow{5}{*}{$\begin{array}{c}\text { Çalışan } \\
\text { Özellikleri }\end{array}$} & Çalışan Sayısı $[3,6,7]$ \\
\hline & Çalışan Deneyimi \\
\hline & Cinsiyeti $[11,12,13]$ \\
\hline & Yaş1 \\
\hline & Eğitim Düzeyi $[4,12,13]$ \\
\hline \multirow{5}{*}{$\begin{array}{c}\text { İşletme } \\
\text { Özellikleri }\end{array}$} & İşletmenin Büyüklüğü $[5,9]$ \\
\hline & İşletmenin Sektörü $[5,6]$ \\
\hline & Ar-Ge Bütçesi $[5,6,7,9]$ \\
\hline & İşletmenin Yaş1 $[3,4,5,7,9]$ \\
\hline & Teknolojik Altyap1 $[7,13]$ \\
\hline \multirow{4}{*}{$\begin{array}{l}\text { İşletme Diş1 } \\
\text { Özellikler }\end{array}$} & Banka Desteği [4] \\
\hline & Kanun/Devlet Desteği $[4,6]$ \\
\hline & Rekabet [7] \\
\hline & Müşteri [7] \\
\hline
\end{tabular}

Çalışma kapsamında değerlendirilen parametrelerden çalışan deneyimi ve yaşı bu çalışma kapsamında dahil edilen parametreler olup, rekabet ve müşteri parametreleri her ne kadar aynı isimle ilgili çalışmada yer almasa da çalışmanın parametreleriyle ilişkili olduğu ancak daha genel adlandırılması gerektiğine karar verilmiştir.

\subsection{Metot}

$\mathrm{Bu}$ çalışmada kriterlerin önceliklendirilmesi için AHP yönteminden faydalanılmıştır. AHP, çok kriterli bir karar verme yöntemidir. Niteliksel ifadelerin, çeşitli hesaplamalar sonucunda niceliksel hale getirilmesine dayanan bu yöntemin uygulamasına literatürde sıkça rastlanmaktadır. İlgili yöntem, Saaty tarafından geliştirilmiş olup adımları şu şekildedir [14-16];

i. Ele alınan problem hiyerarşik bir yapıda gösterilir. Karar vericinin amacı doğrultusunda kriterlerin ve kriterlere ait olan alt kriterlerin belirlenir.

ii. İkili karşılaştırma matrisleri, Çizelge 2'deki skalaya göre oluşturulur. 
Çizelge 2. AHP'de kullanılan temel ölçek skalası

\begin{tabular}{|c|l|}
\hline $\begin{array}{c}\text { Önem } \\
\text { Derecesi }\end{array}$ & \multicolumn{1}{|c|}{ Açıklama } \\
\hline 1 & $\begin{array}{l}\text { İki Seçenekte eşit derecede öneme } \\
\text { sahiptir }\end{array}$ \\
\hline 3 & $\begin{array}{l}\text { Bir kriter diğerine karş1 orta derecede } \\
\text { daha üstündür }\end{array}$ \\
\hline 5 & $\begin{array}{l}\text { Bir kriter diğerine karş1 güçlü derecede } \\
\text { daha üstündür }\end{array}$ \\
\hline 7 & $\begin{array}{l}\text { Bir kriter diğerine karş1 çok güçlü } \\
\text { derecede daha üstündür }\end{array}$ \\
\hline 9 & $\begin{array}{l}\text { Bir kriter diğerine karş1 aşırı düzeyde } \\
\text { daha üstündür }\end{array}$ \\
\hline $2,4,6,8$ & İki ardışı yargı arası değerler \\
\hline
\end{tabular}

iii. İkili karşılaştırma matrislerinin öncelik değerlerine göre kriterlerin ağırlık puanları hesaplanır.

iv. Faktörlerin önem dağılımları belirlenir. önem dağılımlarını belirlemek için, karşılaştırma matrisini oluşturan sütun vektörlerinden yararlanılır ve $n$ adet ve $n$ bileşenli sütun vektörü olușturulur. Sütun vektörlerinin normalize edilmesinden elde edilen $\mathrm{W}_{\mathrm{i}}$ ile matris satırındaki her eleman çarpılıp toplanarak $\mathrm{V}_{1}$ sütun vektörü elde edilir. $\mathrm{V}_{1} / \mathrm{W}_{\mathrm{i}}$ hesaplamaları ile elde edilen $\mathrm{V}_{2}$ sütun vektörünün aritmetik ortalamaları alınarak $\lambda_{\max }$ hesaplanır.

v. Faktör kıyaslamalarındaki tutarlılık ölçülür. Amaç içerisinde yer alan kriter sayısı n olmak koşulu ile tutarlılık göstergesi ve oranı ilgili formülasyonlar ile hesaplanır ve tutarlılık oranı 0,10' a eşit veya küçük olan karşılaştırmaların tutarlı olduğu yorumu yapılır.

vi. Öncelik değerleri belirlenir. En üst hiyerarşik kriterden başlayarak her seviyedeki ağırlıklar çarpılıp toplanır ve öncelik değerleri belirlenir.

\section{BULGULAR VE TARTIŞMA}

Farklı sektörlerden uzmanların puanlamasıyla inovasyon faaliyetlerine etki eden parametrelerin önceliklendirilmeye çalışıldığ 1 bu çalışmada öncelikle ana parametreler değerlendirilmiş ve Çizelge 3 'te sonuçlar sunulmuştur. Çizelgelerde U harfleri uzmanları ifade etmektedir.
Çizelge 3. Ana parametrelere bağlı AHP sonuçları

\begin{tabular}{|l|c|c|c|c|c|c|}
\hline Ana Parametre & $\mathbf{U} \mathbf{1}$ & $\mathbf{U} \mathbf{2}$ & $\mathbf{U} 3$ & $\mathbf{U} 4$ & $\mathbf{U} 5$ & Ort. \\
\hline $\begin{array}{l}\text { Çalışan } \\
\text { Özellikleri }\end{array}$ & 0,649 & 0,242 & 0,626 & 0,678 & 0,776 & 0,594 \\
\hline $\begin{array}{l}\text { Issletme } \\
\text { Özellikleri }\end{array}$ & 0,279 & 0,669 & 0,279 & 0,179 & 0,153 & 0,312 \\
\hline $\begin{array}{l}\text { İletme Diş1 } \\
\text { Özellikler }\end{array}$ & 0,071 & 0,087 & 0,093 & 0,142 & 0,070 & 0,093 \\
\hline
\end{tabular}

Çalışan özellikleri Uzman 1, 3, 4, 5'e göre ilk sırada olup Uzman 2 işletme özelliklerinin daha öncelikli bir parametre olduğunu savunmaktadır. İşletme dışı özellikler ise bütün sektörlerdeki uzmanlara göre son sırada yer almaktadır. Sektör ortalamalarına bakıldığında ise en önemli ana parametrenin çalışan özellikleri olduğu, işletme özelliklerinin ise önem sırasında ikinci sırada yer aldığı; işletme dışı özelliklerin ise en son öncelikli ana parametre olduğu görülmektedir. Böylelikle inovasyon faaliyetlerine etki eden en önemli ana parametrenin çalışanlar ile ilgili özelliklerin olduğu tespit edilmiştir.

Çalışan özellikleri ile ilgili alt parametre kıyaslama sonuçları Çizelge 4'te sunulmuştur.

Çizelge 4. Çalışan özelliklerine bağlı alt parametrelerin AHP sonuçları

\begin{tabular}{|l|c|c|c|c|c|c|}
\hline $\begin{array}{c}\text { Alt } \\
\text { Parametre }\end{array}$ & $\mathbf{U} \mathbf{1}$ & $\mathbf{U} 2$ & $\mathbf{U} 3$ & $\mathbf{U} 4$ & $\mathbf{U} 5$ & Ort. \\
\hline $\begin{array}{l}\text { Çalışan } \\
\text { Sayısı }\end{array}$ & 0,456 & 0,254 & 0,397 & 0,168 & 0,147 & 0,284 \\
\hline $\begin{array}{l}\text { Çalışan } \\
\text { Deneyimi }\end{array}$ & 0,236 & 0,424 & 0,365 & 0,408 & 0,315 & 0,350 \\
\hline Cinsiyeti & 0,124 & 0,036 & 0,104 & 0,040 & 0,050 & 0,071 \\
\hline Yaş1 & 0,104 & 0,116 & 0,071 & 0,103 & 0,121 & 0,103 \\
\hline $\begin{array}{l}\text { Ĕ̆itim } \\
\text { Düzeyi }\end{array}$ & 0,078 & 0,168 & 0,060 & 0,279 & 0,365 & 0,190 \\
\hline
\end{tabular}

Çalışan sayısı Uzman 1 ve 3'e göre işletmelerin inovasyon faaliyetlerine etki eden çalışan özellikleri parametreleridir. Çalışan deneyimi ise Uzman 2 ve 4 tarafindan en önemli parametre olarak belirlenmiş olup, Uzman 5'in bu konudaki önceliklendirmesinin ilk sırasını eğitim düzeyi parametresi yer almaktadır. Cinsiyet ve yaş parametreleri tüm uzmanlara göre en az etkili parametreler olarak belirlenmiştir. Sektör ortalamalarına bakılacak olunursa; Çalışan deneyimi işletmelerde inovasyon faaliyetlerine etki 
eden en önemli parametre olarak belirlenmiş olup, işletmelerdeki çalışan sayısının da yadsınamaz bir önemi olduğu görülmektedir. Çalışanların eğitim düzeylerinin üçüncü sırada yer alması da, işletmelerin inovasyon faaliyetlerini yaparken ilgili parametrenin göz ardı edilmemesi gerektiğinin bir göstergesidir.

İşletme özellikleri alt parametrelerinin kıyaslama sonuçları Çizelge 5'te sunulmuştur. Sonuçlara göre işletme büyüklüğü Uzman 2 ve 4'e göre en önemli parametrelerdir. Ar-Ge bütçesi ise Uzman 1 ve 5'e göre en önemli parametreler olarak belirlenmiştir. Uzman 3 ise işletmelerdeki teknolojik yapının bu durumdaki en önemli unsuru olduğunu göstermiştir. İşletmenin yaşı ve bulunduğu sektörün önemi ise bütün uzmanlara göre son siralarda yer almaktadır. Sektörel uygulama farklılıklarının sonuçlara yansıdığı ilgili özellik karşılaştırmalarında sektör ortalamaları incelenecek olunursa; Ar-Ge bütçesi ve Teknolojik altyapı parametrelerinin ağırlık puanları birbirlerine çok yakın olup en önemli iki parametre olarak belirlenmiştir. İşletmelerin sahip oldukları Ar-Ge bütçeleri ve bu bütçeler ile kurmuş/kuracak oldukları teknolojik altyapı faaliyetlerinin inovasyon yapmalarındaki en önemli unsur oldukları AHP sonuçlarında karşımıza çıkmaktadır. İşletmenin fiziksel büyüklüğü ise bir diğer önemli parametre olarak belirlenmiş olup, işletmenin yaşı dördüncü önemli parametre olarak hesaplanmıştır. İşletmenin bulunduğu sektör ise bu parametreler arasında en az öneme sahip parametre olarak belirlenmiştir.

Çizelge 5. İşletme özelliklerine bağlı alt parametrelerin AHP sonuçları

\begin{tabular}{|l|c|c|c|c|c|c|}
\multicolumn{7}{|c|}{ parametrelerin AHP sonuçlar1 } \\
\begin{tabular}{|l} 
Alt \\
Parametre
\end{tabular} & $\mathbf{U} \mathbf{1}$ & $\mathbf{U} \mathbf{2}$ & $\mathbf{U} \mathbf{3}$ & $\mathbf{U} \mathbf{4}$ & $\mathbf{U} \mathbf{5}$ & Ort. \\
\hline $\begin{array}{l}\text { İşletmenin } \\
\text { Büyüklüğ̈̈ }\end{array}$ & 0,054 & 0,318 & 0,108 & 0,371 & 0,317 & 0,234 \\
\hline $\begin{array}{l}\text { İşletmenin } \\
\text { Sektörü }\end{array}$ & 0,028 & 0,041 & 0,061 & 0,063 & 0,062 & 0,051 \\
\hline $\begin{array}{l}\text { Ar-Ge } \\
\text { Bütçesi }\end{array}$ & 0,463 & 0,282 & 0,194 & 0,245 & 0,336 & 0,304 \\
\hline $\begin{array}{l}\text { İşletmenin } \\
\text { Yaş1 }\end{array}$ & 0,091 & 0,091 & 0,042 & 0,161 & 0,138 & 0,105 \\
\hline $\begin{array}{l}\text { Teknolojik } \\
\text { Altyap1 }\end{array}$ & 0,360 & 0,266 & 0,592 & 0,158 & 0,146 & 0,305 \\
\hline
\end{tabular}

İşletme dışı özelliklere bağlı alt parametrelerin kıyaslama sonuçları Çizelge 6'da sunulmuştur.

Çizelge 6. İşletme dişı özelliklere bağlı alt parametrelerin AHP sonuçları

\begin{tabular}{|l|c|c|c|c|c|c|}
\hline Alt Parametre & U 1 & U 2 & U 3 & U 4 & U 5 & Ort. \\
\hline Banka Desteği & 0,590 & 0,463 & 0,060 & 0,410 & 0,324 & 0,369 \\
\hline $\begin{array}{l}\text { Kanun/ } \\
\text { Devlet Desteği }\end{array}$ & 0,193 & 0,327 & 0,076 & 0,321 & 0,359 & 0,255 \\
\hline Rekabet & 0,159 & 0,132 & 0,584 & 0,127 & 0,193 & 0,239 \\
\hline Müşteri & 0,057 & 0,076 & 0,279 & 0,140 & 0,123 & 0,135 \\
\hline
\end{tabular}

İşletme dışı özelliklerden olan banka desteği alt parametresi Uzman 1, 2 ve 4'e göre en önemli parametredir. Uzman 3'e göre rekabet parametresi, Uzman 5'e göre ise Kanun/Devlet desteği parametresi en önemli parametreler olarak belirlenmiştir. Sektör ortalamaları incelendiğinde banka desteği, işletmelerin inovasyon faaliyetlerini gerçekleştirirken etkilendikleri en önemli işletme dışı özellik parametresi olarak belirlenmiştir. Kanun/devlet desteği ve rekabet parametreleri ise birbirlerine yakın ağırlıklar ile sonraki sıralardaki parametrelerdir. Müşteri parametresi ise son sırada yer almaktadır.

Çizelge 3, 4, 5, 6'daki AHP değerlendirmeleri yapılırken tutarlılık indeksleri hesaplanmış olup, her birinin 0,10 ' un altında olduğu bulunmuştur.

Bütün alt parametre ağırlıkları, ana parametrelerin ağırlıkları ile çarpılarak kıyaslama yapılmış olup, nihai önceliklendirme tamamlanmıştır. İlgili sonuçlar Çizelge 7'de sunulmuştur.

Çizelge 7. Nihai parametre önceliklendirme sonuçları

\begin{tabular}{|l|c|}
\hline Parametreler & A ğırlık \\
\hline Çalışan Deneyimi & 0,2081 \\
\hline Çalışan Sayıs1 & 0,1694 \\
\hline Eğitim Düzeyi & 0,1133 \\
\hline Teknolojik Altyap1 & 0,0952 \\
\hline Ar-Ge Bütçesi & 0,0950 \\
\hline İşletmenin Büyüklüğ̈̈ & 0,0730 \\
\hline Yaş1 & 0,0615 \\
\hline Cinsiyeti & 0,0424 \\
\hline Banka Desteği & 0,0345 \\
\hline İşletmenin Yaş1 & 0,0328 \\
\hline Kanun/Devlet Desteği & 0,0238 \\
\hline Rekabet & 0,0223 \\
\hline İşletmenin Sektörü & 0,0161 \\
\hline Müşteri & 0,0126 \\
\hline
\end{tabular}


Bütün alt parametreler ana parametrelerinin ağırlıklarına göre önceliklendirildiğinde, çalışan deneyiminin işletme inovasyon faaliyetlerine etki eden en önemli parametre olduğu görülmüştür. Çalışan sayısı ve eğitim düzeyleri de ilk üç sırada bulunan parametrelerdir. Teknolojik altyapı ve işletmelerin Ar-Ge bütçeleri de sıralamanın ilk siralarında yer alan önemli parametreler olarak belirlenmiştir. İşletmelerin inovasyon faaliyetlerine en az etki eden parametreler ise rekabeti işletmelerin bulundukları sektör ve müşteri parametreleridir.

\section{SONUÇLAR VE ÖNERILER}

İşletmelerin inovasyon faaliyetlerine etki eden parametrelerin belirlenip önceliklendirildiği bu çalışmada beş farklı sektördeki uzman görüşlerinden yararlanılmıştır. Her bir uzmandan yapılması istenen ikili kıyaslama puanlarına göre AHP yöntemi ile parametreler arası siralamalar gerçekleştirilmiştir. Parametreler literatür araştırması sonucunda derlenmiş ve çalışan özellikleri, işletme özellikleri ve işletme dış1 özellikleri şeklinde üç ana bölüme ayrılmıştır. Uzmanlar tarafindan üç ana grubun önceliklendirilmesi yapıldığında çalışan özelliklerine ait parametrelerin en önemli olduğu sonucuna varılmıştır. Çalışanlar ile ilgili özelliklerin inovasyon faaliyetlerine etki ettiği görüşü sektör ortalamalarında yüksek bir ağırlıkla ortaya konulmuştur. İşletmeleri ayakta tutan ve gelişmelerine katkı sağlayan en önemli etken kuşkusuz ki o işletmelerdeki çalışanlardır. Bu çalışanlara ait deneyimlerin, eğitim düzeylerinin ve ilgili işletmelerdeki toplam çalışan sayılarının nihai parametre önceliklendirme sonuçlarına göre de ilk üç sırada yer alması bu sonucu destekler niteliktedir. Çalışanların deneyimleri ne kadar fazla olursa, inovasyon faaliyetlerine katkıları bir o kadar fazla olacaktır. Ayrıca bir işletmede fazla sayıda çalışan bulunması, daha farklı fikirlerin, katkıların ve beyin firtınalarının olumlu sonuçlanmasını doğuracaktır. Farklı varyasyonlardaki eğitim düzeyleri de hiyerarşik yapılara katkı sağlayıp takım çalışmalarındaki rollerin daha net anlaşılmasını sağlayacaktır. Çalışan özelliklerine ait diğer iki özellik yaş ve cinsiyet olarak belirlenmiş ve bu iki özellik her ne kadar ilgili ana parametre içerisinde son sıralarda yer alsa da nihai parametre önceliklendirme sonuçları içerisinde orta sıralarda yer almıştır. Literatürde cinsiyet farklılığının inovasyon yapma eğilimlerinin etkilediği sonucuna [11-13] paralel olarak çıkan bu önceliklendirme sonucu, yaş ile çalışan deneyiminin etkileşimde olabileceğinin de göstergesidir. $\mathrm{Bu}$ sonuçlara göre işletmeler inovasyon faaliyetlerine eğilim gösterdiklerinde çalışanlarının deneyimlerine uygun yapıdaki gelişmeleri takip etmeleri ve gerçekleştirmek istedikleri inovasyon faaliyetleri içerisinde çalışanlarını da dahil ederek onlara ait özellikleri göz ardı etmemeleri gerekmektedir. İşe alımlarda, takım kurmalarda, grup çalışmalarında önem arz edeceği için, işletmelerin gelişmelerine yadsınamaz şekilde katkı sağlayacak olan çalışan özelliklerine dikkat etmeleri gerekmektedir.

İşletme özelliklerinin sektör ortalamalarına göre ikinci önemli parametre olarak hesaplanması ile işletmelerin inovasyon faaliyetlerine etki eden en önemli iki alt parametre işletmelerin teknolojik altyapıları ve Ar-Ge bütçeleri olarak belirlenmiştir. Ağırlıkları birbirlerine çok yakın olan bu iki alt parametrenin birbirlerini tamamlayan iki ayr1 kavram olduğu ortaya konulmuştur. İşletmeler yıllık ya da beş yıllık bütçelerini oluştururken Ar-Ge bütçelerine ayıracakları payı kuracakları ya da geliştirecekleri teknolojik altyapılarına uygun bir biçimde gerçekleştirmeleri gerekmektedir. Çalışan özelliklerinin hemen ardından önem derecelerine sahip olan bu iki parametrenin inovasyon faaliyetlerine etki ettiği ve öncesindeki parametrelerle bir bütün olduğu gözden kaçırılmamalıdır. İşletmenin fiziksel büyüklüğü de bir diğer önemli alt parametre olup, kurulacak ekipmanların ve ya çalıştırılacak personelin sayısını etkileyeceğinden önemli bir parametre olduğu görülmektedir. İşletme özellikleri içerisinde en az öneme sahip olan alt parametre işletmenin sektörüdür. Günümüzde inovasyon kavramının hemen hemen her alanda yer alması, sektörel farklılıkların etki düzeyini yitirmesine sebep vermiştir. $\mathrm{Bu}$ sebeple uzman görüşlerinin ortalamalarının alınarak çalışma sonuçlarının sektörel ortalamalara göre yorumlanması, 
çalıșmanın bu sonucuna göre de doğru bir yaklaşımda ele alındığının göstergesi sayılabilir.

Uzman görüşlerine göre en az öneme sahip olan işletme dışı özellikler içerisindeki banka destekleri sektörel ortalamalara göre en önemli parametre olarak belirlenmiş, nihai parametre önceliklendirme sonuçlarına göre çalışan özelliklerine ait alt parametrelerin bitiminin hemen ardından bir önceliğe sahip olmuştur. Belli deneyimde, eğitim düzeyinde çalışana sahip; belli bir teknolojik alt yapısı ve Ar-Ge bütçesine sahip olan işletmelerin çalışmalarını ilerletmek ve geliştirmek amacıyla banka desteğine başvurabilmeleri ve bu desteklerden faydalanarak gelişimlerine katkı sağlamaları çok önemlidir. Kanun ve devlet desteği ile bu çalışmaların desteklenmesi de işletmelerin inovasyon faaliyetlerini gerçekleştirmelerini teşvik etmektedir. Özellikle KOBİ kapsamında bulunan işletmelerin banka veya kanun/devlet destekleriyle kendilerini geliştirerek üretim veya hizmet sunmaları çok önemlidir. Ülke kalkınmasında çok önemli bir paya sahip olan KOBİ'lerin desteklenmesi açısından bu iki alt parametre çok önemli bir paya sahiptir. İşletme dışı özellikler arasında yer alan ve nihai önceliklendirme sonuç tablosunda son iki sirada yer alan rekabet ve müşteri parametreleri ise yine önemli parametreler olup, aksiyon planlarında son siralarda yer alan parametrelerdir.

Sonuç olarak bu çalışmada işletmelerin inovasyon faaliyetlerini gerçekleştirirken en çok hangi parametrelerden etkilendikleri belirlenip önceliklendirilmeye çalıșılmıștır. Bu sayede bu çalışma işletmelerin inovasyon faaliyetlerini gerçekleştirirken hangi kriterlere ne kadar önem vermeleri yönünden karar vericilere 1 șı tutması yönünden önem arz etmektedir. Çalışmanın kısıtlarını beş farklı sektörden alınan uzman görüşleri ve toplamda on üç alt parametre oluşturmaktadır. İleriki çalışmalarda daha farklı sektörlerden uzmanlara ulaşarak sektör ortalamalarının tekrar hesaplanması ve daha farklı parametrelerin de dahil edilerek araştırmanın derinleştirilmesi planlanmaktadır.

\section{KAYNAKLAR}

1. Rogers, E. M., 1983. Diffusion of innovations ( $3^{\text {rd }}$ ed.). New York: The Free Press, Newyork

2. TÜIKK Yenilik Araştırması, 2016, http://www.tuik.gov.tr/PreHaberBultenleri.do?i $d=24864$

3. Çetin, K., Gedik, H., 2017. İşletmelerde İnovasyona Etki Eden Faktörler: Karaman İli Örneği. Uluslararası Yönetim İktisat ve İşletme Dergisi, 13(5), 160-172.

4. Şendoğdu, A.A., Öztürk, Y.E., 2013. KOBİlerde İnovasyon Yapma Eğilimi ile İnovasyon Performans Başarı Derecesi Arasındaki İlişkinin Araştırılması. Ömer Halisdemir Üniversitesi İktisadi ve İdari Bilimler Fakültesi Dergisi, 6(2), 104.

5. Kılıç, R., Keklik, B., 2012. Kobi'lerde Genel Firma Özelliklerinin İnovasyon Uygulamalarına Etkisi: Balıkesir İlinde Bir Araştırma. Erciyes Üniversitesi İktisadi ve İdari Bilimler Fakültesi Dergisi, (39), 93-118.

6. Kılıç, R., Örücü, E., Savaş, A., 2011. KOBI'lerde İnovasyon Stratejileri ve İnovasyon Yapmayı Etkileyen Faktörler; Bir Uygulama. Dogus University Journal, 12(1), 58-73.

7. Çalıpınar, H., Baç, U., 2007. Kobi’lerde İnovasyon Yapmayı Etkileyen Faktörler ve Bir Alan Araştırması, Ege Akademik Bakış Dergisi, Y1l: 7, Sayı: 2.

8. Romero, I., Martínez-Román, J. A., 2012. SelfEmployment and Innovation Exploring The Determinants of Innovative Behavior in Small Businesses, Research Policy, 41, 178-189.

9. Shefer, D., Frenkel, A., 2005. R\&D, Firm Size and Innovation: An Empirical Analysis, Technovation 25, 25-32.

10. Hameed, M.A., Counsell, S., 2014. Establishing Relationships Between Innovation Characteristics and it Innovation Adoption in Organisations: A Meta-Analysis Approach. International Journal of Innovation Management, 18(01), 1450007.

11. Garcia, C., Gonzalez-Moreno, A., Jose SaezMartınez, F., 2013. Gender Diversity Within R\&D Teams: Its Impact on Radicalness of Innovation. Innovation, 15(2), 149-160. 
12. Marvel, M.R., Lee, I.H.I., Wolfe, M.T., 2015. Entrepreneur Gender and Firm Innovation Activity: A Multilevel Perspective. Engineering Management, IEEE Transactions on, 62(4), 558-567.

13. Subramanian, A.M., Choi, Y.R., Lee, S.H., Hang, C.C., 2015. Linking Technological and Educational Level Diversities to İnnovation Performance. The Journal of Technology Transfer, 1-23.

14. Saaty, R.W., 1987. The Analytic Hierarch Process: What it is and How it is used, Mathl Modelling, 9(3-5), 161-176.

15. Vaidya, O.S., Kumar, S., 2006. Analytic Hierarchy Process: An Overview of Applications, European Journal of Operational Research, 169, 1-29.

16. Saaty, T.L., 1980. The Analytic Hierarchy Process. New York: McGraw Hill. International, Translated to Russian, Portuguese, and Chinese, Revised Editions, Paperback (1996, 2000), Pittsburgh: RWS Publications. 